\title{
Honing Safety and Reliability Aspects in the Evolution of Eurocode 7
}

\author{
Trevor Orr ${ }^{1}$ \\ ${ }^{1}$ Department of Civil, Structural and Environmental Engineering, Trinity College Dublin, University of \\ Dublin, Dublin 2, Ireland. E-mail: torr@tcd.ie
}

Ten years after their publication, the Eurocodes, including Eurocode 7 for geotechnical design, are being revised taking into account experiences with their use and developments in design concepts and practices since their publication to produce a second generation of the Eurocodes. The aims in this evolution of Eurocode 7 include that it should:

1. Improve its ease of use, particularly for day-to-day calculations.

2. Harmonize its structure with the other Eurocodes and other supporting documents.

3. Include sections for new or important subjects such as numerical methods, reinforced soil and ground improvement.

4. Allow room for more generic such as seismic design and rock mechanics.

This paper explains how it is planned to address these aims and how the revised Eurocode 7 should improve the management of safety and reliability of geotechnical designs. The revised Eurocode 7 will have three parts, the first part giving the general rules to be applied to the geotechnical aspects of the design of buildings and civil engineering works, the second part providing the requirements for the assessment of ground properties from ground investigations, and the third part providing the specific requirements for the design of particular geotechnical structures. It will be explained how, to improve its ease of use, the existing three Design Approaches in Eurocode 7, which involve many tables of partial factors, are being replaced by a series of Design Combinations, which are combinations of partial factors presented in a single table for all design situations and which enable either material or resistance factoring to be adopted for a particular design situation. A novel feature in the revised Eurocode 7 is the plan to include importance factors, related to consequence classes, which are applied to modify the partial factors and allow for reliability differentiation depending on the consequences of failure. In the third part, there will be separate sections for the requirements and methods for common geotechnical design situations, such as the design of spread and pile foundations, retaining structures and slopes and cuttings developed from the existing sections in Eurocode 7, plus new sections for the design of ground improvement and reinforced soil structures. In addition it is planned that the revised Eurocode 7 will provide more guidance on generic aspects, such as rock design and serviceability limit state design.

Keywords: Eurocode 7; evolution; safety; reliability; design combinations; importance factors.

Proceedings of the 7th International Symposium on Geotechnical Safety and Risk (ISGSR)

Editors: Jianye Ching, Dian-Qing Li and Jie Zhang

Copyright (c) ISGSR 2019 Editors. All rights reserved.

Published by Research Publishing, Singapore.

ISBN: 978-981-11-2725-0; doi:10.3850/978-981-11-2725-0_key4-cd 